\title{
Black Lives Matter
}

\author{
Avner Maximiliano de Paulo ${ }^{1}$, Carlos Eduardo Oliveira de Souza ${ }^{1}$, \\ Bruna Guimarães Lima e Silva ${ }^{2}$, Flávio Luiz Schiavoni ${ }^{1}$, Adilson Siqueira ${ }^{2}$ \\ ${ }^{1}$ Arts Lab in Interfaces, Computers, and Everything Else - ALICE \\ ${ }^{2}$ Nucleus of Art and Sustainability - NAST \\ Federal University of São João del-Rei - UFSJ São João del-Rei - MG - Brazil \\ avnerpaulo.mg@gmail.com, carlosbolin@hotmail.com \\ limaesilvaguimaraes@gmail.com, fls@ufsj.edu.br, negrados@ufsj.edu.br
}

\begin{abstract}
The Brazilian police killed 16 people per day in 2017 and 3/4 of the victims were black people. Recently, a Brazilian called Evaldo Rosa dos Santos, father, worker, musician, and black, was killed in Rio de Janeiro with 80 rifle bullets shot by the police. Everyday, the statistics and the news show that the police uses more force when dealing with black people and it seems obvious that, in Brazil, the state bullet uses to find a black skin to rest. Unfortunately, the brutal force and violence by the state and the police to black people is not a problem only in this country. It is a global reality that led to the creation of an international movement called Black Lives Matter (BLM), a movement against all types of racism towards the black people specially by the police and the state. The BLM movement also aims to connect black people of the entire world against the violence and for justice. In our work, we try to establish a link between the reality of black people in Brazil with the culture of black people around the world, connecting people and artists to perform a tribute to the black lives harved by the state force. For this, the piece uses web content, news, pictures, YouTube's videos, and more, to create a collage of visual and musical environment merged with expressive movements of a dance, combining technology and gestures. Black culture beyond violence because we believe that black lives matter.
\end{abstract}

\section{Introduction}

Black Lives Matter (BLM) is a movement that began in 2013 founded by three black activists (Alicia Garza, director of the National Domestic Workers Alliance, Patrisse Cullors, director of the Coalition to End Sheriff Violence in Los Angeles and immigrant rights activist Opal Tometi) as a form of demonstration against the acquittal of neighborhood watchman George Zimmerman in the murder of 17year-old student Trayvon Martin. However, in 2014, after the murder of two more black youths, Michael Brown and Eric Garner, the movement gained strength and became nationally recognized. Today, the BLM movement has become an organization that aims to fight not only against police brutality, but also against the conditions that oppress blacks around the world, economically, socially and politically [1] [2]. The movement can be found in the Internet with the hash tag \#BlackLivesMatter.

With the current neofascist wave and the growth of right-wing governments around the world, we are seeing an increasingly stimulus to the return of movements such as the Ku Klux Klan, which bring the black population of the world into concern for possible setbacks in their rights. In Brazil, it is not different. Brazil is the non African country with the biggest afro descendant population in the world and one of the last country in the world to abolish slavery. Nowadays, a black person is 3 times more propense to be killed and most part of the murders in the country happened to afro Brazilians. Marielle Franco, a black city councillor from Rio, the only black female representative and one of seven women on the 51-seat council was killed in 2018. The killers were two former policeman. According to Human Rights Watch, the police force in the state of Rio de Janeiro, Brazil, killed more than 8,000 people between 2005 and 2015, 3/4 of them were black men. At the same time, the African culture strongly influenced the Brazilian culture and most part of the traditional Brazilian music and rhythms can be considered black music.

Certainly, the black people influenced not only the Brazilian culture but several traditional music around the world, mostly associated with drums, chorales and voices and almost never associated with technology. That is our tribute to the BLM movement, a performance that can be a utterly new form to put black people in the music, associating black skins with technology in a contemporary music scenario.

\section{The Performance}

The Black Lives Matter performance is a tribute to the BLM movement. According to the BLM's site, the purpose of the movement is to connect the black people around the world to seek justice and fight against the violence and racism, mainly by the police and the state. We wanted to approach this discussion to the computer music area. Our performance is a connection between music, dance and projections in a kind of improvisation dance and composition where computers and technology is putted together. Then, acting like an protest act.

Two musicians play in the computer a sum of YouTube videos, news and other online content, creating a collage of different historical moments of black people in art and news. This disruptive and sometimes awkward piece allows to put together anonymous and famous people, Samba and Blues, CNN and Globo. Merging layers of YouTube videos, the musicians create an visual and sonic environment playing in the same stage B.B. King and Naná Vasconcelos, with famous speeches and reporters. 


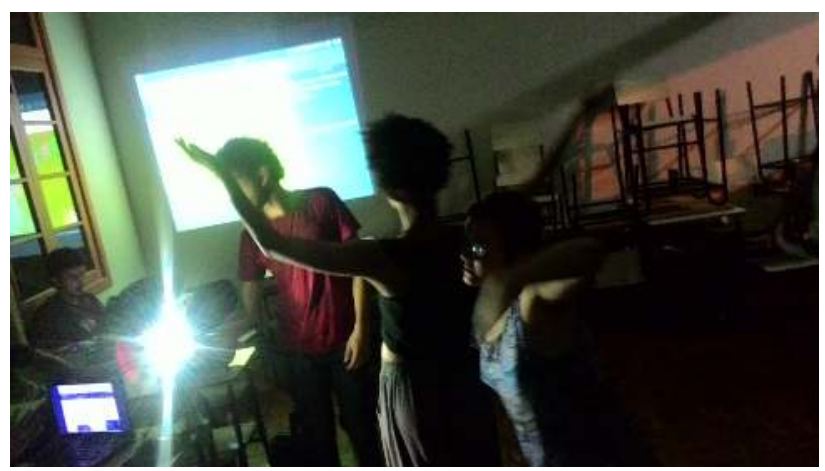

Figure 1: Initial experiments of the performance.

The musical layer of the spectacle is mainly inspired by Pierre Schaeffer's Musique concretè [3], were we work with clippings from various videos, making a collage based on a pre-established score. The result is a set of samples being played in parallel, generating something chaotic and fun, due to the diverse origins of the clippings. The visual part intents to be a "white box", showing through two projectors, everything that's on the computer screens, with the tool and score open, side by side, and the hole process of the collage, being generated live.

Behind this projections, the performer realizes a dance, inspired in Anne Teresa de Keersmaeker \& Michele Anne de Mey's Fase (1982) and Steve Reich's Music [4], addressing some points of the aesthetics worked on this performance, where the main idea is for the actress to dance with her shadow (see Figure 3), based on slightly off-synchronized music, in order to bring about changes in performance and music in a gradual way, to make the exchanges of context for the public almost imperceptible.

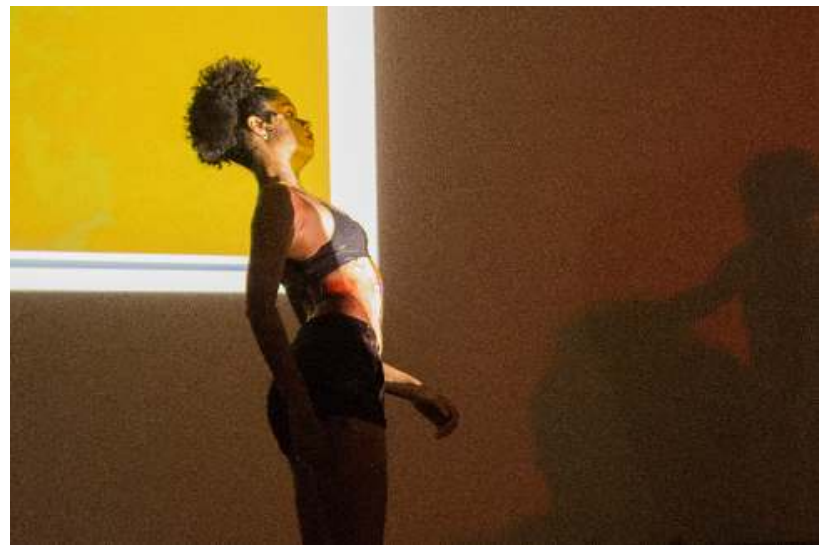

Figure 2: The projections over the performer's skin, creating a shadow on the wall.

\section{Program Notes}

The "Black Lives Matter" movement is about violence inflicted on Black communities by the state and vigilantes. Through the usage of the web as a tool to make collage art with online content, we try to approach this social question to the reality of Brazil, without disregarding its origin, merging this two realities and putting on the scene the hard reality of black people and also several artists and important figures for these cultures. Beyond that, which is shown by the projections and the sound, we have the presence of a corporal performer, completing the show with the shadow produced by her dance and the light of the projections reflecting on her skin.

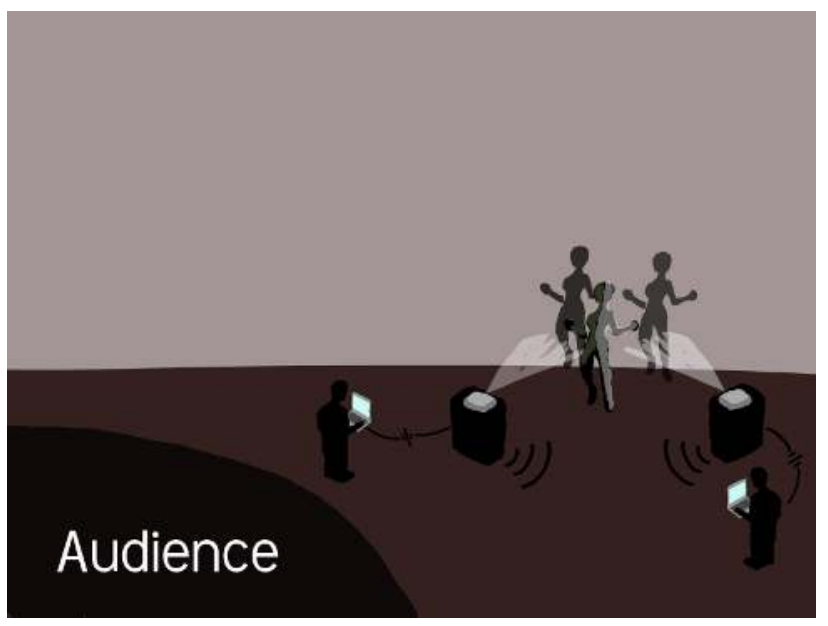

Figure 3: Stage plot

\section{Technical Details}

- Performance time: 23 minutes.

- Instrumentation: Computers and projectors.

- Musicians

- Avner Maximiliano de Paulo

- Carlos Eduardo Oliveira de Souza

- Performer

- Bruna Guimarães Lima e Silva

- Intended venue: Cultural Center of UFSJ

- Setup time: about 30-40 minutes.

- Technical requirements

$$
\begin{aligned}
& \text { - } 2 \text { Speakers } \\
& \text { - } 2 \text { Projectors }
\end{aligned}
$$

\section{Acknowledgments}

Authors would like to thanks to all ALICE and NAST members that made this research and development possible. The authors would like also to thank the support of the funding agencies CNPq and FAPEMIG.

\section{References}

[1] Russell Rickford. Black lives matter: Toward a modern practice of mass struggle. In New Labor Forum, volume 25, pages 34-42. SAGE Publications Sage CA: Los Angeles, CA, 2016.

[2] Alicia Garza, O Tometi, and P Cullors. A herstory of the\# blacklivesmatter movement. Are all the women still white, pages 23-28, 2014.

[3] Carlos Palombini. Machine songs v: Pierre schaeffer: From research into noises to experimental music. Computer Music Journal, 17(3):14-19, 1993.

[4] Renate Bräuninger. Structure as process: Anne teresa de keersmaeker's fase (1982) and steve reich's music. Dance Chronicle, 37(1):47-62, 2014. 